\title{
The Prevalence of Cerebral Palsy in British Columbia, 1991-1995
}

\author{
Les Smith, Karen D. Kelly, Glenda Prkachin, Donald C. Voaklander
}

\begin{abstract}
Objective: To quantify the prevalence of cerebral palsy (CP) in British Columbia within a four-year birth cohort. Methods: The study was a population-based record linkage study of a birth cohort of British Columbian children born between April 1, 1991 and March 31, 1995. Cases were identified by the presence of International Classification of Diseases, Version 9 (ICD-9) diagnostic code " 343 " recorded at three years of age or older or by having the ICD-9 diagnostic code " 343 " recorded prior to the third birthday with two confirmatory diagnoses within the first three years of life through a record search of the BC Medical Services Plan billing files for the fiscal years 1991 to 1995. Results/Conclusion: This research has provided an estimate of the prevalence of CP in the four-year birth cohort 1991 to 1995 in British Columbia. An aggregate prevalence rate of CP was measured as 2.68 per 1000 live births, and a congenital rate was measured at 2.57 for the same population. Birth weight and gestational age demonstrated a significant relationship with the development of CP. This study should lend credence to the establishment of a CP register in British Columbia.
\end{abstract}

RÉSUMÉ: La prévalence de la paralysie cérébrale en Colombie-Britannique de 1991 à 1995 . Objectif : Le but de cette étude était d'évaluer la prévalence de la paralysie cérébrale (PC) en Colombie Britannique dans une cohorte de naissance de 4 ans. Méthodes : Il s'agit d'une étude de population effectuée au moyen d'une recherche de la banque de données de facturation du BC Medical Services Plan d'une cohorte de naissance d'enfants nés en Colombie-Britannique entre le 1er avril 1991 et le 31 mars 1995. Les cas étaient identifiés par la présence du code diagnostique ICD-9 « 343 » inscrit lorsque l'enfant avait trois ans ou plus ou, s'il était plus jeune, lorsque le code « 343 » était accompagné de deux diagnostics confirmant la PC dans les trois premières années de vie. Résultats / Conclusion : Le taux de prévalence global de la PC a été évalué à 2,68 par 1000 naissances vivantes et le taux congénital à 2,57 dans la même population. Il existait une relation significative entre la présence de la PC et le poids à la naissance et l'âge gestationnel. Cette étude ajoute foi à l'établissement d'un registre de la PC en ColombieBritannique.

Can. J. Neurol. Sci. 2008; 35: 342-347

Cerebral palsy (CP) is considered to be the most common, most disabling chronic childhood disorder affecting approximately two-three per 1000 livebirths. ${ }^{1}$ Cerebral palsy describes a group of permanent disorders of movement and posture, causing activity limitation, that are attributed to nonprogressive disturbances that occurred in the developing fetal or infant brain. The motor disorders of cerebral palsy are often accompanied by disturbances of sensation, perception, cognition, communication and behaviour, by epilepsy, and by secondary musculoskeletal problems. ${ }^{2}$ Cerebral palsy is not an etiologic diagnosis, but a clinical descriptive term. ${ }^{2}$

The majority of studies report the prevalence of $\mathrm{CP}$ as the number of cases per 1000 livebirths/neonatal survivors, with most of the research on the epidemiology of $\mathrm{CP}$ being based on cerebral palsy registries. ${ }^{3}$ One study has used a population-based record linkage. ${ }^{4}$

Limited research has been conducted in Canada regarding the epidemiology of CP. At the time of publication, there is one $\mathrm{CP}$

From Northern Health (LS); Psychology (GP), University of Northern British Columbia, Prince George, BC; Nursing (KDK), School of Public Health (DCV), University of Alberta, Edmonton, AB, Canada.

Received January 2, 2007. Final Revisions Submitted February 8, 2008. Reprint requests to: Northern Health, Professional Practice Strategy, \#600-299 Victoria Street, Prince George, BC, V2L 4E7, Canada. 
registry operating in the Province of Quebec. The purpose of this research project was to use population-based record linkage to measure $\mathrm{CP}$ in the Province of British Columbia (BC).

\section{Methods}

\section{Study Population}

The methods for ascertaining the study population for this project were based on the work of Robertson et al. (1998). ${ }^{4} \mathrm{~A}$ four-year birth cohort from April 1, 1991 to March 31, 1995 was selected using population-based record linkage.

Inclusion Criteria: Subjects were identified by documenting diagnostic codes used by physicians and hospitals during the years reviewed for this study. The diagnostic codes used were from the International Classification of Diseases, Version 9 (ICD-9) (International Classification of Diseases, 1977). ${ }^{5}$ Cases were identified by the presence of the ICD-9 diagnostic code "343" for CP recorded at three years of age or older, or by having the ICD-9 diagnostic code " 343 " recorded prior to the third birthday with two confirmatory diagnoses within the first three years of life. Each child had a minimum of six years of post-birth follow-up information in order to confirm the presence of $\mathrm{CP}$, including children over the age of three. Children in each cohort were followed over a variable tracking period with an average of eight years. In addition to the above codes for $\mathrm{CP}$, codes for congenital abnormalities of the nervous system (742) and other congenital abnormalities $(743-757,759)$ were used to clarify a child's diagnosis of $\mathrm{CP}$ as children with these diagnoses have a high risk for developing the condition. ${ }^{6}$

In order to determine whether children with $\mathrm{CP}$ may have acquired the disorder, the following codes were searched: malignant neoplasms of the brain (191), inflammatory disease of the nervous system (320-326), other conditions of the brain and nervous system $(348,349)$, intracranial haemorrhage (430-432), aborted sudden infant death syndrome (798), fracture of the skull (800-840), other injuries (950-959, 990-995), intracranial injury excluding skull fracture (850-854), late effects of injuries (905909), and poisoning (960-989). ${ }^{4}$
Exclusion Criteria: Children whose health insurance was not continuous of the six-year follow-up period were excluded. Also, children with the ICD-9 diagnostic codes identifying chromosomal abnormalities (758.x) and spina bifida (741.x) were not included in this research, although these are not disorders that may be exclusive of CP. Children found to have a progressive neurological disorders $(330,331,334,335,340$, 341 ) were excluded as they would not meet the definition of $\mathrm{CP}^{2}$

\section{Record Linkage}

To identify cases, a record search of the British Columbia Medical Services Plan billing files and the BC Hospital Separation Abstracts for the fiscal years 1991/1992, 1992/1993, $1993 / 1994$, and 1994/1995 was conducted. The data gathered from these sources were linked longitudinally at the individual level to all further BC Medical Services Plan activity continuing until March 31, 2001. These data were longitudinally linked to any subsequent inpatient treatment recorded in the BC Hospital Separation Abstracts for the same time period. Using information from BC Vital Statistics, the cohort was linked to birth and death records. The birth records provided information on birth weight and gestational age at delivery. The death records included causes and dates of death for any of the children in the four-year cohort. Contributing co-morbid conditions, including congenital abnormalities/anomalies and common childhood diseases such as asthma, were also tabulated.

\section{Data Analysis}

The prevalence of $\mathrm{CP}$ was calculated for each year of the birth cohort using the year-specific population of British Columbian children with health insurance registration of at least six years from the time of birth as the denominator. The numerator for each of the birth cohorts was the sum of the individuals in each cohort meeting the inclusion criteria for $\mathrm{CP}$ who have at least six years of continuous health insurance registration from the time of birth. An aggregate prevalence rate was calculated for congenital and acquired (post-natal) CP. Finally, prevalence rates were stratified by birth weight (0-999 grams, 1000-1499 grams;

Table 1: Number and proportion of children with $\mathrm{CP} *$ by age at first recorded diagnosis

\begin{tabular}{lcccccccccccc}
\hline Cohort (birth year) & \multicolumn{1}{c}{} & \multicolumn{1}{c}{ Children's Age at Diagnosis } & \multicolumn{4}{c}{$\begin{array}{c}\text { Total Individuals } \\
\text { Diagnosed }\end{array}$} \\
& $\mathbf{0 - 1}$ & $\mathbf{1}$ & $\mathbf{2}$ & $\mathbf{3}$ & $\mathbf{4}$ & $\mathbf{5}$ & $\mathbf{6}$ & $\mathbf{7}$ & $\mathbf{8}$ & $\mathbf{9}$ & $\mathbf{1 0}$ & \\
Cohort 1 (1991-1992) & 8 & 21 & 20 & 18 & 12 & 12 & 16 & 9 & 2 & 9 & 5 & 132 \\
Cohort 2 (1992-1993) & 13 & 26 & 10 & 21 & 14 & 15 & 9 & 9 & 10 & 1 & 0 & 128 \\
Cohort 3 (1993-1994) & 20 & 25 & 14 & 23 & 17 & 16 & 6 & 3 & 2 & 0 & 0 & 126 \\
Cohort 4 (1994-1995) & 25 & 12 & 8 & 21 & 19 & 14 & 7 & 5 & 0 & 0 & 0 & 111 \\
Total & 66 & 84 & 52 & 88 & 62 & 57 & 38 & 26 & 14 & 10 & 5 & 497 \\
\% of Total & 13.3 & 16.9 & 10.5 & 16.7 & 12.5 & 11.5 & 7.6 & 5.2 & 2.8 & 2 & 1 & 100 \\
\hline
\end{tabular}

* includes 20 children with CP of probable post-natal cause 
Table 2: Prevalence of childhood CP* by cohort in British Columbia

\begin{tabular}{lcccc}
\hline & Number of & Number in & & \\
Cohort (birth year) & Cases & Cohort & Prevalence & $\mathbf{9 5 \%} \mathbf{~ C l}$ \\
Cohort 1 (1991-1992) & 132 & 46,064 & 2.87 & $2.38,3.36$ \\
Cohort 2 (1992-1993) & 128 & 46,175 & 2.77 & $2.29,3.25$ \\
Cohort 3 (1993-1994) & 126 & 46,296 & 2.72 & $2.25,3.19$ \\
Cohort 4 (1994-1995) & 111 & 47,211 & 2.35 & $1.91,2.78$ \\
Total & 497 & 185,746 & 2.68 & $2.44,2.92$ \\
\hline
\end{tabular}

* includes 20 children with probable acquired CP. CI = confidence interval

1500-2499 grams; 2500-3999 grams and >4000 grams), gestational age (<26 weeks; 26-30 weeks, 31-35 weeks, 36-40 weeks and $>41$ weeks) and geographic health region. The results were compared using the chi-square statistic, assuming a significance level of $\leq 0.05$.

This study assumed a prevalence rate of $\mathrm{CP}$ of $2 \%$ and an annual birth rate of 10 per 1000 population. ${ }^{7}$ Based on this estimate, a prevalence rate difference of $0.4 \%$ was detectable for analyses comparing those rates for low birth weight and short gestational age to normative values. ${ }^{8}$ All data were entered into and analyzed using SPSS, Version 12.0. ${ }^{9}$

Research ethics approval was obtained from the University of Northern British Columbia Research Ethics Board, Prince George, BC, Canada. Data stewards within the Ministry of Health for the Province of British Columbia approved the research plan and data linkage.

\section{Results}

On reviewing the physician's codes and the accompanying ICD-9 diagnostic code for $\mathrm{CP}$, it appeared that paediatricians were responsible for recording the diagnosis in $39.2 \%$ of cases and orthopaedic surgeons in $35.6 \%$ of cases, whereas general practitioners recorded the diagnosis $18.3 \%$ of the time. Less than $1 \%$ of the cases in this cohort were identified by a neurologist.

The number and proportion of children diagnosed with CP in each of the birth cohorts is recorded in Table 1. Cerebral palsy was diagnosed in 497 of the children over this four-year cohort, yielding an aggregate prevalence rate of 2.68 per 1000 (95\% CI $=2.44,2.92)$. Although there appears to be a decreasing trend in prevalence rates among the cohorts, chi-square analysis for trend was not significant $\left(\chi^{2}=0.200, d f=1, p=0.6551\right)$ (Table 2). Approximately two-fifths $(41.0 \%)$ of the children were diagnosed before their third birthday. Twelve children $(2.4 \%)$ died prior to their tenth birthday. Twenty $(4.1 \%)$ children of the 485 confirmed living cases up to their tenth birthday had a definite post-natal event that could be considered the probable cause of the $\mathrm{CP}$. Five children were identified with progressive neurological disorders and were therefore not included in this study. Due to migration out of the province, it was not possible to track the number of children with non-continuous health insurance.

Table 3: Number and proportion of children with congenital CP in the cohort by birth weight*

\begin{tabular}{|c|c|c|c|c|}
\hline $\begin{array}{l}\text { Birth Weight Groups } \\
\text { (grams) }\end{array}$ & Cohort Size & $\begin{array}{l}\text { Number of } \\
\text { Children with } \\
\text { Congenital } \\
\text { Cerebral Palsy }\end{array}$ & $\begin{array}{l}\text { Prevalence by } \\
\text { Birth Weight } \\
\text { in the Cohort } \\
\text { Group per } 1000\end{array}$ & $95 \% \mathrm{Cl}$ \\
\hline $0-999$ & 617 & 41 & 66.5 & $46.8,86.2$ \\
\hline 1000-1499 & 829 & 44 & 53.1 & $37.8,68.4$ \\
\hline $1500-2499$ & 7,782 & 78 & 10.0 & $7.8,12.2$ \\
\hline 2500-3999 & 150,470 & 273 & 1.81 & $1.61,2.01$ \\
\hline$>4000$ & 25,409 & 41 & 1.61 & $1.11,2.11$ \\
\hline
\end{tabular}

* 639 children had an unknown birth weight 
Table 4: Number and proportion of children with congenital CP by gestational age*

\begin{tabular}{|c|c|c|c|c|}
\hline & & & Prevalence & \\
\hline & & Number of & Rate & \\
\hline & & Children with & by Gestational & \\
\hline Gestational Age & & Congenital & Age per 1000 & \\
\hline (weeks) & Cohort Size & Cerebral Palsy & In Cohort & $95 \% \mathrm{Cl}$ \\
\hline$<26$ & 382 & 20 & 52.3 & $30.0,74.6$ \\
\hline $26-30$ & 992 & 67 & 67.5 & $51.9,83.1$ \\
\hline $31-35$ & 5,470 & 59 & 10.8 & $8.1,13.5$ \\
\hline $36-40$ & 142,188 & 262 & 1.84 & $1.62,2.06$ \\
\hline$>41$ & 37,529 & 66 & 1.75 & $1.33,2.17$ \\
\hline Total & 186,561 & 474 & 2.54 & $2.31,2.87$ \\
\hline
\end{tabular}

*3 cases had an unknown gestational period

Table 5: Number and proportion of children with cerebral palsy by British Columbian Health Region $(1991-1995) *$

\begin{tabular}{lcccc}
\hline $\begin{array}{l}\text { Health } \\
\text { Region }\end{array}$ & $\begin{array}{c}\text { Number of Cases of } \\
\text { Cerebral Palsy per } \\
\text { Health Region }\end{array}$ & $\begin{array}{c}\text { Number of Births } \\
\text { per Region in } \\
\text { Cohort }\end{array}$ & $\begin{array}{c}\text { Incidence of } \\
\text { Cerebral Palsy } \\
\text { per Region }\end{array}$ & $\mathbf{9 5 \% \text { Cl }}$ \\
Interior & 60 & 28,054 & 2.14 & $1.60,2.68$ \\
Fraser & 191 & 65,989 & 2.89 & $2.48,3.30$ \\
Vancouver Coastal & 108 & 42,046 & 2.57 & $2.09,3.05$ \\
Vancouver Island & 82 & 29,412 & 2.79 & $2.48,3.10$ \\
Northern & 53 & 18,640 & 2.84 & $2.45,3.23$ \\
Unknown & 3 & 638 & 4.7 & $-0.6,10.0$
\end{tabular}

* 967 British Columbia residents were born out-of-province

The probable causes for acquired $\mathrm{CP}$ were determined from the ICD-9 codes. These included traumatic brain injury (3), meningitis (2), malignant neoplasm of the brain (2), acquired paralysis (1), acquired hemiparesis (1), progressive neurological disorder (2), anomalies of the circulatory system (1), occlusion of the cerebral artery (1), and other conditions of the brain and nervous system (7).

The prevalence rate of congenital $\mathrm{CP}$ for this birth cohort was 2.57 per $1000(95 \% \mathrm{CI}=2.34,2.80)$. Forty-four percent of the children diagnosed with $\mathrm{CP}$ were female, and $56 \%$ were male.

Of the 477 children with congenital CP, code " 742 " for other congenital anomalies was recorded for 25 (5.2\%) cases. Code "742" details conditions such as encephalocele, reduction deformities of the brain, congenital hydrocephalus, other specific abnormalities of the brain, spinal cord or nervous system, and unspecified anomalies of the brain spinal cord or nervous system. ${ }^{4-5}$ Fourteen children $(2.9 \%)$ had one or more codes identifying other congenital anomalies, codes 743-747 and 759. Therefore, 39 children (8.2\%) diagnosed with congenital CP were coded as demonstrating congenital anomalies. Of those children with acquired CP, 4 (20\%) coded 742, while $2(10 \%)$ coded 743-747 or 759. Children with the diagnoses spina bifida (code 741) or chromosomal abnormalities (code 758) were excluded from this cohort, and were therefore not identified.

Table 3 illustrates the number and proportion of children with congenital $\mathrm{CP}$ in this cohort by birth weight. Children born with a birth weight of less than 1000 grams in this study had a prevalence rate of 66.5 per 1000 for this cohort. Children with a birth weight between 1000-1499 grams had a prevalence of 53.1 per 1000, while those weighing between 1500-2499 grams had a prevalence rate of 10.0 per 1000 . This distribution was statistically significant $\left(\chi^{2}=895.92, d f=4\right)$ demonstrating the 
likelihood of being born with CP may be related to a low birth weight.

The number and proportion of children with congenital CP by gestational age are recorded in Table 4. Children born at less than 26 weeks in this study had a prevalence rate of congenital CP of 52.3 per 1000 in this cohort. Those born between 26-30 weeks had the highest prevalence of $\mathrm{CP}$, measured at 67.5 per 1000 . The prevalence rate decreased in subsequent gestational periods from 10.8 for children born between 31-35 weeks, to 1.84 for children born between $36-40$ weeks, to 1.75 for children born after 41 weeks gestation. This distribution was statistically significant $\left(\chi^{2}=1,912.22, d f=4\right)$ illustrating that gestational age may be related to the development of $\mathrm{CP}$.

Table 5 reports the geographic distribution of children with $\mathrm{CP}$ in British Columbia in each health region. The health regions listed are representative of the cohorts studied, but were restructured in 2001. The Interior Health Region recorded the lowest incidence rate of 2.14 per $1000(95 \% \mathrm{CI}=1.60,2.68)$, while the Fraser Health Region recorded the highest incidence rate of 2.89 per $1000(95 \% \mathrm{CI}=2.48,3.30)$ in this four-year birth cohort. No statistically significant difference was found among the health regions using the chi-square statistic $\left(\chi^{2}=4.97, d f=\right.$ 5 ). Therefore, no differences in the proportion of children with $\mathrm{CP}$ were observed among geographic regions in the Province of British Columbia.

\section{Discussion}

The aggregate rate of $\mathrm{CP}$ in British Columbian children born between 1991 and 1995 was measured at 2.68 per 1000 . The congenital rate was measured at 2.57 per 1000 for the same cohort. These rates fall within the reported range of 2.0-3.0 per 1000 from previous studies throughout the world. ${ }^{10-22}$ The prevalence rates reported for children with $\mathrm{CP}$ in this cohort by birth weight $(<1000$ grams $=66.5,1000-1499$ grams $=53.1$, and 1500-2499 grams $=10.0)$ were similar to those reported by Hagberg et al (2001) ${ }^{15}$ who studied a cohort born between 1991 and 1994 in Sweden. The prevalence rate for children born of very low birth weight $(<1500$ grams) was lower than that of the previous Canadian study. ${ }^{4}$ In comparison to our findings, a recent study examining the trends in $\mathrm{CP}$ among infants of very low birth weight (VLBW) or born prematurely ( $<32$ weeks) in 16 European centres found that the prevalence rate among VLBW infants fell from 60.6 per 1000 live born VLBW infants in 1980 to 39.5 per 1000 VLBW infants in $1996 .{ }^{23}$ More than $65 \%$ of children in our study had a birth weight of 2500 grams or greater, similar to that found in the other Canadian study. ${ }^{4}$

In contrast to the Alberta study by Robertson et al, ${ }^{4}$ the number of general practitioners making or confirming the diagnosis of $\mathrm{CP}$ in this study was quite high (18.3\% versus $1.1 \%$ ). This could occur for a number of reasons. Unlike in Alberta, children with $\mathrm{CP}$ are not normally referred to a tertiary care centre for a multidisciplinary assessment due to distance to the tertiary care facilities and cost involved for travel. Therefore, it is difficult for the diagnosis of CP to be made by specialists such as developmental paediatricians, paediatric neurologists, or paediatric neurosurgeons unless children and their families live in large urban centres such as Vancouver or Victoria where the tertiary care centres are located.

Like all data sources, limitations also exist with record linkage of administrative data such as inaccurate coding of the diagnosis or procedures made by multiple physicians, underreporting of comorbid conditions, difficulty in recording the timing of events and causal inferences, and limited information about health status and clinical outcomes. ${ }^{24}$ The Medical Services Plan (MSP) payment information master file represents services that have been reimbursed during the fiscal year with payment for physicians being based on the ICD-9 diagnostic codes. It is known that approximately $86 \%$ of the standard ICD-9 codes are covered in the MSP claims database, demonstrating that the information in the MSP database is comprehensive in scope across the range of possible disease. Greater than $96 \%$ of paid services and paid amounts to physicians are associated with the ICD-9 codes contained in the MSP database. ${ }^{25}$ For these reasons, it is likely that inaccurate coding of the diagnosis or procedure and underreporting of comorbid conditions is reduced. In the majority of cases, the ICD-9 codes obtained for this study did not include a fourth digit, thereby limiting this study's ability to report the nature and type of the motor disorder.

Nevertheless, the use of population-based record linkage has a number of advantages. These include the ability to select large sampling frames, the elimination of recall bias, and the minimization of subject contact. Record linkage of administrative data is also cost effective and permits the researcher to generalize results, as administrative databases typically encompass large segments of the population. ${ }^{24}$

This study adds important epidemiological evidence concerning the prevalence of $\mathrm{CP}$ in Canada. It is evident that $\mathrm{CP}$ affects a large number of children in the province of British Columbia, even with advances in neonatal and perinatal care. The results of this study can also contribute valuable information for future research, as it has provided a baseline estimate of the prevalence of CP in British Columbia. In addition, through this study, credence may be lent to the establishment of a $\mathrm{CP}$ register in the Province of British Columbia. This would allow Canadian researchers the same advantages as those in Europe, Australia and the United Kingdom where $\mathrm{CP}$ registers have been established for many years, specifically, the ability to investigate the origins and outcomes of $\mathrm{CP}$ within a geographically defined population. ${ }^{26} \mathrm{~A}$ register would allow researchers to monitor trends related to $\mathrm{CP}$ and quality of life of children with $\mathrm{CP}$, as well as provide longitudinal outcome data related to the costs of caring for children with $\mathrm{CP}^{26-28}$

\section{ACKNOWLEDGEMENTS}

This study was funded through a grant received from the Medical Services Foundation of British Columbia. The authors thank Ms. Rosemary Armour of the British Columbia Vital Statistics Agency for her kind assistance in providing population denominators.

\section{REFERENCES}

1. Surveillance of Cerebral Palsy in Europe. Surveillance of cerebral palsy in Europe: a collaboration of cerebral palsy surveys and registers. Dev Med Child Neurol. 2000;42:816-24.

2. Rosenbaum P, Paneth N, Leviton A, Goldstein M, Bax M, Damiano $\mathrm{D}$, et al. A report: the definition and classification of cerebral palsy April 2006. Dev Med Child Neurol. 2007;47 Suppl 109: 8-14. 
3. Uldall P, Michelsen SI, Topp M, Madsen M. The Danish cerebral palsy registry. Dan Med Bull. 2001;48:161-3.

4. Robertson CMT, Svenson LW, Joffres MR. Prevalence of cerebral palsy in Alberta. Can J Neurol Sci. 1998;25:117-22.

5. International Classification of Diseases. Manual of the international statistical classification of diseases, injuries and causes of death, 9th Revision; 1977.

6. Walstab JE, Bell RJ, Reddihough DS, Brennecke SP, Bessell CK, Beischer NA. Factors identified during the neonatal period associated with risk of cerebral palsy. Aust N Z J Obstet Gynaecol. 2004:44:342-6.

7. British Columbia Vital Statistics Agency. Government of British Columbia Information Bulletin. 2002; Issue 042: Available from: http://os8150. pb.gov.bc.ca/4dcgi/nritem?5535.

8. Kahn HA, Sempos CT. Statistical methods in epidemiology. Toronto: Oxford University Press; 1989.

9. SPSS Inc. SPSS 12.0. Chicago: SPSS; 2003

10. Mutch L, Alberman E, Hagberg B, Kodama K, Velickovic Perat M. Cerebral palsy epidemiology: Where are we now and where are we going? Dev Med Child Neurol. 1992;34:547-55.

11. Murphy CC, Yeargin-Allsopp M, Decoufle P, Drews CD. Prevalence of cerebral palsy among ten-year-old children in metropolitan Atlanta, 1985 through 1987. J Pediatr. 1993; 123:S13-20.

12. Hagberg B, Hagberg G, Olow I. The changing panorama of cerebral palsy in Sweden. VI. Prevalence and origin during the birth year period 1983-1986. Acta Paediatr. 1993;82:387-93.

13. Hagberg B, Hagberg G, Olow I, Wendt L. The changing panorama of cerebral palsy in Sweden. VII. Prevalence and origin in the birth year period 1987-90. Acta Paediatr. 1996;85:954-60.

14. Colver AF, Gibson M, Hey EN, Jarvis SN, Mackie PC, Richmond S. Increasing rates of cerebral palsy across the severity spectrum in north-east England 1964-1993. Arch Dis Child Fetal Neonatal Ed. 2000;83:F7-12.

15. Hagberg B, Hagberg G, Beckung E, Uvebrant P. Changing panorama of cerebral palsy in Sweden. VIII. Prevalence and origin in the birth year period 1991-94. Acta Paediatr. 2001;90:271-7.
16. Stanley F, Blair E, Alberman E. Cerebral palsies: epidemiology \& causal pathways. Clinics in developmental medicine No. 151. London: Mac Keith Press; 2000.

17. Krageloh-Mann I, Hagberg G, Meisner C, Haas G, Eeg-Olofsson KE, Selbmann HK, et al. Bilateral spastic cerebral palsy - a comparative study between south-west Germany and western Sweden. II: epidemiology. Dev Med Child Neurol. 1994;36: 473-83.

18. MacGillivray I, Campbell DM. The changing pattern of cerebral palsy in Avon. Paediatr Perinat Epidemiol. 1995;9:146-55.

19. Meberg A, Broch H. A changing pattern of cerebral palsy. Declining trend for incidence of cerebral palsy in the 20-year period 197089. J Perinat Med. 1995;23:395-402.

20. Pharoah POD, Cooke T, Johnson MA, King R, Mutch L. Epidemiology of cerebral palsy in England and Scotland, 198489. Arch Dis Child Fetal Neonatal Ed. 1998;79:F21-5.

21. Parkes J, Dolk H, Hill N, Pattenden S. Cerebral palsy in Northern Ireland: 1981-93. Paediatr Perinat Epidemiol. 2001;15:278-86.

22. Topp M, Uldall P, Greisen G. Cerebral palsy in eastern Denmark, 1987-90: implications for neonatal care. Paediatr Perinat Epidemiol. 2001;15:271-7.

23. Platt MJ, Cans C, Johnson A, Surman G, Topp M, Torrioli MG, et al. Trends in cerebral palsy among infants of very low birth weight $(<1500 \mathrm{~g})$ or born prematurely $(<32$ weeks $)$ in 16 European centres: a database study. Lancet. 2007;369:43-50.

24. Stanley FJ, Croft ML, Gibbins J, Read AW. A population database for maternal and child health research in Western Australia using record linkage. Paediatr Perinat Epidemiol. 1994;8:433-47.

25. Hu W. Diagnostic codes in MSP claim data: Summary report. Program monitoring and information management branch, resource management division, Medical Services Plan; 1996.

26. Cans C, Surman G, McManus V, Coghlan D, Hensey O, Johnson A. Cerebral palsy registries. Semin Pediatr Neurol. 2004;11:18-23.

27. Liptak GS, Accardo PJ. Health and social outcomes of children with cerebral palsy. J Pediatr. 2004;145:S36-41.

28. Majnemer A, Mazer B. New directions in the outcome evaluation of children with cerebral palsy. Semin Pediatr Neurol. 2004;11: 11-17. 